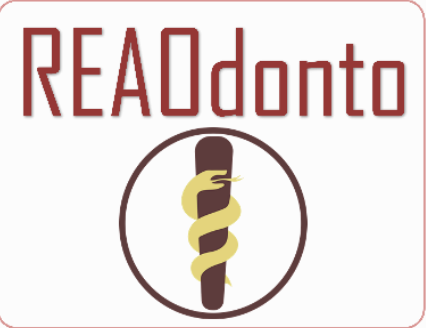

Revista Eletrônica Acervo Odontológico

\section{RELATO DE CASO}

Recebido em: 3/2020

Aceito em: 4/2020

Publicado em: 6/2020

\title{
A sífilis e suas manifestações bucais: relato de caso clínico
}

\author{
Syphilis and its oral manifestations: clinical case report
}

Sífilis y sus manifestaciones orales: informe clínico de caso

Liana Carla Souza de Andrade Batista ${ }^{1}$, Letícia de Oliveira Santos ${ }^{1}$, Mariana Cecília de Oliveira Terêncio ${ }^{1}$, Nycole Valois Rocha Vieira da Silva ${ }^{1}$, Ronaldo de Carvalho Raimundo ${ }^{1}$, Márcia Maria Fonseca da Silveira1, Vânia Cavalcanti Ribeiro da Silva1*.

\begin{abstract}
Resumo: Esse artigo buscou apresentar o caso de um paciente masculino, com 26 anos de idade, que procurou a clínica de estomatologia por apresentar lesões múltiplas, indolores, irregulares, esbranquiçadas, em cavidade bucal. Exibia também linfonodo visualmente aumentado e palpável em região submentoniana. Com hipótese clínica de infecção sexualmente transmissível, foram solicitados exames complementares de diagnóstico. O paciente revelou positividade ao teste de triagem para a Sífilis e ao teste de Mantoux, sendo encaminhado ao serviço médico para confirmação diagnóstica e tratamento. Na sequência, foi submetido a testes sorológicos específicos que confirmaram o diagnóstico de Sífilis e excluíram outras infeções. $O$ paciente foi tratado com Penicilina G Benzatina e logo após a primeira dose da medicação, apresentou regressão total das lesões situadas em boca. A sífilis, ainda hoje, é considerada um problema de saúde pública e um grande desafio reside no reconhecimento das manifestações localizadas em áreas extragenitais. Embora a cavidade bucal não seja o sítio de acometimento preferencial, é uma região de envolvimento frequente. Assim sendo, o exame clínico detalhado associado à solicitação de exames sorológicos não podem ser negligenciados e o cirurgião dentista deve estar capacitado para reconhecer as lesões suspeitas dessa infecção.
\end{abstract}

Palavras-chave: Sífilis, Manifestações bucais, Medicina bucal.

Abstract: This article sought to present the case of a 26 -year-old male patient who came to the stomatology clinic for presenting multiple, painless, irregular, whitish lesions located in the oral cavity. He also had a visually enlarged and palpable lymph node in the submental region. With a clinical hypothesis of sexually trasmitted infection, complementary diagnostic tests were requested. The patient was positive for the screening test for Syphilis and the Mantoux test and was referred to the medical service for diagnostic confirmation and treatment. Subsequently, he underwent specific serological test that confirmed the diagnosis of Syphilis and ruled out other infections. The patient was treated with Penicillin G Benzatin and immediately after the first dose of the medication, he presented total regression of the lesions located in the mouth. Syphilis, even today, is a public health problem and a major challenge lies in the recognition of manifestations located in extragenital sites. Although the oral cavity is not the preferred site of involvement, it is a region of frequent involvement.

1 Faculdade de Odontologia de Pernambuco, Camaragibe - PE. *E-mail: vaniacavrs@gmail.com 
Therefore, the detailed clinical examination associated with the request for serological tests cannot be neglected and the dentist must be able to recognize the suspected lesions of this infection.

Keywords: Syphilis, Oral manifestations, Oral medicine.

Resumen: Este artículo buscó presentar el caso de un paciente masculino de 26 años que acudió a la clínica de estomatología por presentar múltiples lesiones blanquecinas irregulares e indoloras ubicadas en la cavidad oral. También tenía un ganglio linfático visualmente agrandado y palpable en la región submental. Con una hipótesis clínica de infección de transmisión sexual, se solicitaron pruebas de diagnóstico complementarias. El paciente fue positivo para la prueba de detección de sífilis y la prueba de Mantoux, y luego fue derivado al servicio médico para confirmación de diagnóstico y tratamiento. Posteriormente, se sometió a pruebas serológicas específicas que confirmaron el diagnóstico de sífilis y descartaron otras infecciones. El paciente fue tratado con Penicilina G Benzatina, e inmediatamente después de la primera dosis de la medicación, presentó regresión total de las lesiones localizadas en la boca. La sífilis, incluso hoy, es un problema de salud pública y un desafío importante radica en el reconocimiento de las manifestaciones ubicadas en sitios extragenitales. Aunque la cavidad oral no es el sitio preferido de participación, es una región de participación frecuente. Por lo tanto, el examen clínico detallado asociado con la solicitud de pruebas serológicas no puede ser descuidado y el dentista debe ser capaz de reconocer las sospechas de lesiones de esta infección.

Palabras clave: Sífilis, Manifestaciones orales, Medicina oral.

\section{INTRODUÇÃO}

A sífilis é uma infecção sexualmente transmissível (IST) conhecida desde o século XV, mas ainda hoje traz impactos profundos para a saúde e vida da população mundial. É uma doença exclusiva do ser humano, causada pelo espiroqueta anaeróbico Treponema pallidum, cuja biologia é pouco conhecida devido a impossibilidade do seu cultivo em meios artificiais. (KALININ Y, 2016; SEIBT CE e MUNERATO MC, 2016; SOUZA BC, 2017; DE ANDRADE RS, et al., 2018; SOLIS RN, et al., 2018).

Mesmo com a descoberta da penicilina, no século XX, eliminar a sífilis continua sendo um grande desafio. Dados da Organização Mundial de Saúde (OMS) revelam que a cada dia são contraídas, por pessoas de 15 a 49 anos, em todo o mundo, mais de um milhão de ISTs curáveis, e só no ano de 2016, foram 6,3 milhões de novos casos de sífilis no mundo (WHO, 2017).

Ao ser contraída durante a gestação, a sífilis provoca cerca de 305 mil mortes fetais e neonatais por dia e expõe 215 mil lactentes a um risco aumentado de morte por prematuridade, baixo peso ao nascer ou doenças congênitas. No adulto, se não tratada, cerca de $25 \%$ dos infectados desenvolverão sequelas clínicas importantes, a exemplo de doenças neurológicas (meningite, acidente vascular cerebral, disfunção do nervo craniano, alterações auditivas, oftálmicas e oculares), doenças cardiovasculares (aortite, aneurisma, insuficiência da válvula aórtica, estenose do óstio da coronária) e lesões granulomatosas, podendo evoluir para o óbito (AVELLEIRA JCR e BOTTINO G, 2006; BRASIL, 2010; WHO, 2017).

Sobre os meios de transmissão da sífilis, o contato sexual desprotegido com parceiro infectado constituise no principal, mas também a via hematogênica, através de transfusão sanguínea ou contato direto com sangue contaminado (forma adquirida), não pode ser esquecida. Uma terceira via de transmissão é a vertical, na qual o agente etiológico passa da mãe para o filho durante a gestação ou parto (forma congênita) (ANGUS J, et. al., 2006; KENT ME e ROMANELLI F, 2008; SEIBT CE e MUNERATO MC, 2016; DE ANDRADE RS, et al., 2018).

Duas a três semanas após a inoculação do Treponema pallidum no organismo surgem as lesões primárias, geralmente pápulas indolores que ulceram e formam o cancro (protossifiloma). O principal local de inoculação são os órgãos genitais, mas outras áreas também podem ser acometidas, a exemplo da cavidade bucal, onde as lesões costumam envolver língua, gengiva, palato mole ou lábios, associadas à linfadenopatia submandibular e cervical (BRASIL, 2010; CARMONA-LORDUY M, et al., 2018; STREIGHT KL, et al., 2019). 
Se não tratada, a sífilis alterna períodos sintomáticos e assintomáticos, com características clínicas, imunológicas e histopatológicas distintas, divididas em três fases, a primária, a secundária e a terciária. Nas fases primária e secundária, a possibilidade de transmissão da doença é maior. Depois, há um período praticamente assintomático, no qual o treponema fica latente no organismo. Na terceira fase, a doença retorna com agressividade, acompanhada de complicações graves (BRASIL, 2010; CARMONA-LORDUY M, et al., 2018).

Lesões bucais podem ocorrer em quaisquer das três principais fases da doença, sendo confundidas com outras afecções mais prevalentes. Podem também ser a única manifestação da infecção. Apesar da multiplicidade de formas, as manifestações mais comuns incluem a presença de úlceras indolores ou lesões com bordas irregulares e esbranquiçadas que podem se apresentar distribuídas na mucosa bucal e na orofaringe (EYER-SILVA WDA, et al., 2017; DE ANDRADE RS, et al., 2018). O grande desafio é a diversidade de aspectos clínicos que dificulta o diagnóstico precoce da doença e compromete o tratamento, podendo o paciente evoluir para um quadro de sífilis terciária (FRANCO ACM, 2008; CARMONA-LORDUY M, et al., 2018).

O diagnóstico da doença se baseia nos achados do exame clínico, testes sorológicos e, em algumas situações, em exames de imagem. O teste rápido, que é um teste de triagem, é disponibilizado no sistema único de saúde (SUS). É simples e a leitura do resultado é disponibilizada em, no máximo, 30 minutos. Nos casos reagentes, um teste confirmatório é indicado. A biópsia é reservada para os casos em que as lesões não regridem totalmente (WHO, 2016).

O tratamento de escolha para a sífilis é a penicilina, que age interferindo na síntese da parede celular do Treponema pallidum. A Penicilina Benzatina costuma ser a mais empregada e o planejamento do tratamento varia em função do estágio da doença, grau de comprometimento neurológico do paciente e condição imunológica. De acordo com o guia para tratamento da sífilis da OMS, no caso da doença primária, secundária e latente recente (com menos de dois anos de evolução) o tratamento deve ser a administração intramuscular, em dose única, de 2,4 milhões UI de Penicilina Benzatina. Já para a sífilis latente tardia (com mais de dois anos de evolução) ou latente com duração ignorada e sífilis terciária é recomendada a aplicação semanal, por três semanas, de 2,4 milhões UI de Penicilina Benzatina, por via intramuscular. Terminado o tratamento, é importante acompanhar o paciente com testes não treponêmicos quantitativos, a cada seis meses, por um período de dois anos. Durante esse monitoramento, o aumento de dois ou mais títulos no teste sorológico sugere reinfecção ou tratamento inadequado, visto que a infecção pela Treponema Pallidum não confere imunidade ao paciente (ORTEGA KL, et al., 2004; LITTLE JW, 2005; WHO, 2016).

Por ser a cavidade bucal o sítio extragenital mais acometido pela sífilis, o Cirurgião Dentista (CD) precisa conhecer a história natural da doença e suas características clínicas, pois tem papel relevante no diagnóstico precoce e controle da infecção. O objetivo desse trabalho é relatar um caso clínico de sífilis cujo diagnostico foi estabelecido a partir das manifestações bucais, visando a contribuir com dados para o aprimoramento do $C D$.

\section{DETALHAMENTO DE CASO}

Paciente do gênero masculino, 26 anos de idade, procurou a clínica de estomatologia da Faculdade de Odontologia da Universidade de Pernambuco por apresentar há cerca de três semanas várias lesões em boca. Durante a anamnese negou qualquer problema sistêmico e afirmou não possuir relacionamento fixo com ninguém, apenas encontros ocasionais. O exame físico extrabucal revelou importante aumento de volume em região submentoniana (Figura 1). 
Figura 1 - Linfadenopatia. Aumento de volume em região submentoniana.

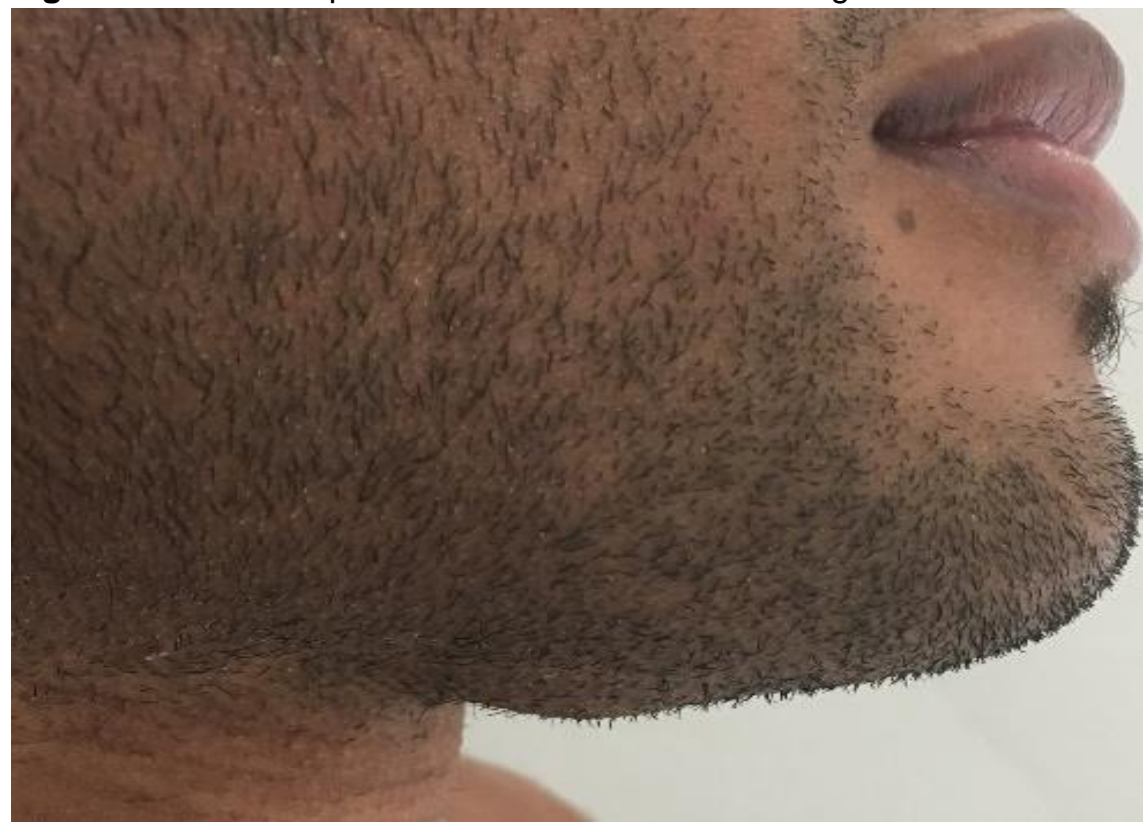

Fonte: Batista LCSA, et al., 2020.

O exame intrabucal evidenciou a existência de lesões indolores, de formato irregular, coloração esbranquiçada, localizadas em diversos pontos da mucosa bucal, mais especificamente no palato, lábio, mucosa jugal e língua (Figura 2).

Figura 2 - Diferentes padrões de apresentação clínica da sífilis.

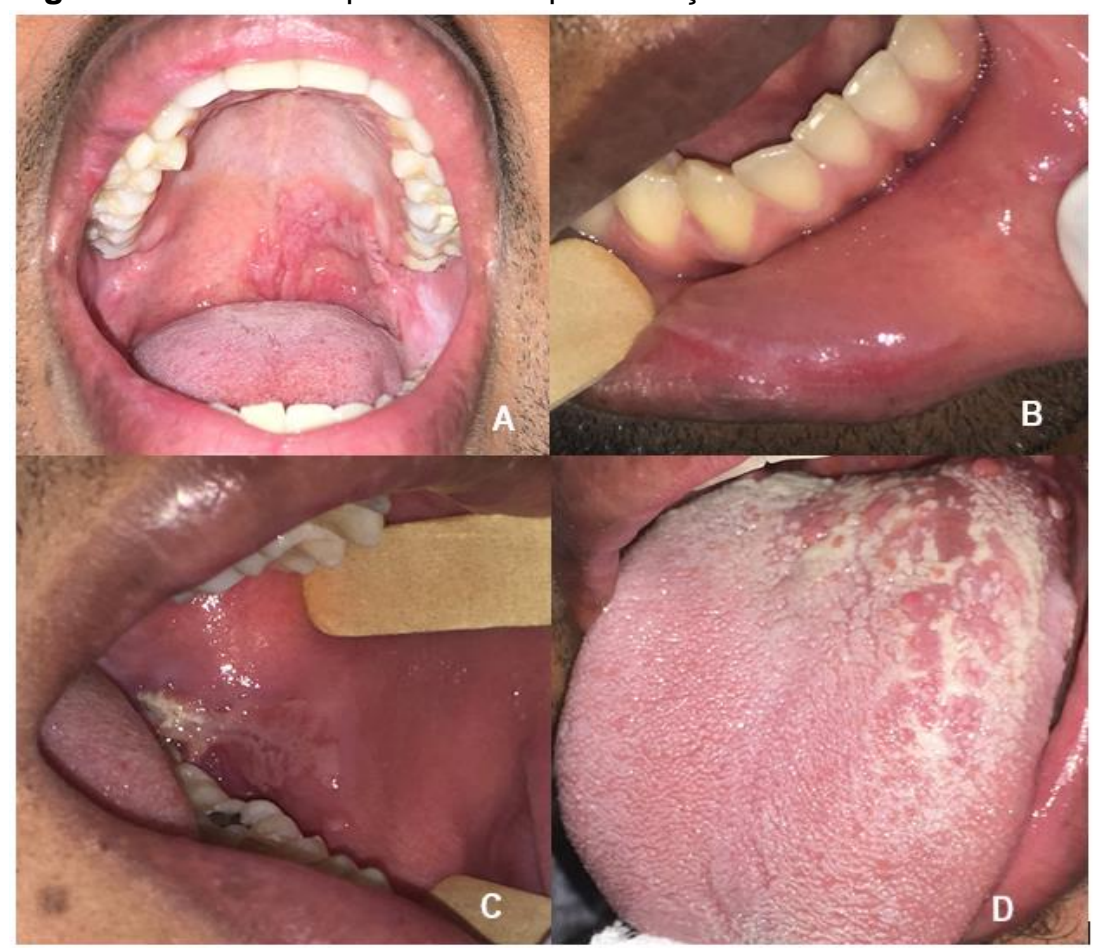

Legenda: (A) Placa esbranquiçada sobre fundo eritematoso localizada em palato mole. (B) Placa branco acinzentada, discreta, em mucosa interna de lábio inferior. (C) Lesão ulcerada de fundo esbranquiçado em mucosa jugal. (D) Placa mucosa em dorso de língua ocasionando aumento de volume e modificação do aspecto lingual. Fonte: Batista LCSA, et al., 2020. 
Com base nos achados clínicos e suspeita de IST, foram solicitados exames complementares. Os exames hematológicos (hemograma e coagulograma) apresentaram valores normais. A ultrassonografia revelou a presença de imagens homogêneas, ovaladas, medindo $2,6 \times 1,5 \mathrm{~cm}$ e 1,7 x 0,6 cm em região submentoniana, sugestivas de linfonodos. O Venereal Disease Research Laboratory (VDRL) qualitativo e o teste de Mantoux revelaram positividade. O paciente foi então encaminhado à clínica médica para realização de testes específicos, os quais confirmaram o diagnostico presuntivo de sífilis e descartaram outras infecções (Tuberculose, Hepatites B e C e HIV). Não sendo o paciente alérgico à penicilina foi instituída a terapia de escolha, 2,4 milhões UI de Penicilina G Benzatina, administrada por via intramuscular, com aplicações semanais, por três semanas. Logo após a primeira aplicação, o paciente apresentou regressão total das lesões bucais (Figura 3) e continua em monitoramento clínico.

Figura 3 - Aspecto clínico da cavidade bucal após tratamento para sífilis.

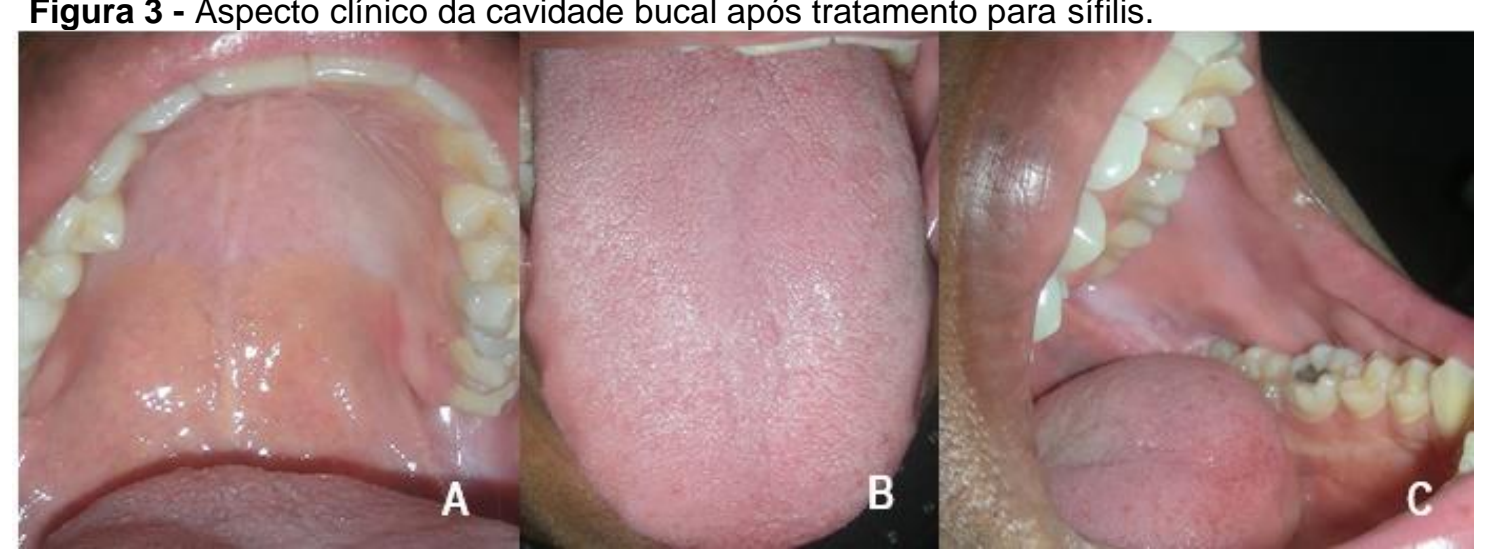

Legenda: (A) Total regressão da lesão situada em palato. (B) Aspecto de normalidade do dorso lingual, com restabelecimento das papilas. (C) Aspecto de normalidade da mucosa jugal.

Fonte: Batista LCSA, et al., 2020.

\section{DISCUSSÃO}

Apesar dos avanços obtidos ao longo dos anos nas áreas de prevenção, diagnóstico e tratamento das ISTs e da facilidade na difusão de informações, essas infecções continuam a desafiar a saúde pública mundial. A OMS estima que sejam contraídas mais de um milhão de ISTs diariamente no mundo, com tendência ao agravamento do quadro e profundo impacto na saúde e vida da população. A sífilis, após um período de redução global na incidência, reemergiu. No Brasil, cerca de 900.000 novos casos são diagnosticados a cada ano, aumentando o risco de contágio de outras ISTs, principalmente o HIV, já que as lesões sifilíticas são locais propícios para a entrada do vírus no organismo humano (DE ANDRADE RS, et al., 2018; WHO, 2016; WHO, 2017).

Mesmo sendo uma doença curável, com tratamento de custo acessível e disponível na rede pública, a sífilis ainda não está controlada. O Brasil vive uma epidemia reconhecida pelas autoridades de saúde desde 2016. Dados do boletim epidemiológico mostram que a taxa de detecção da sífilis adquirida aumentou de 59,1 por 100 mil habitantes, em 2017, para 75,8 por 100 mil habitantes, em 2018 . Um aumento de $28,3 \%$. 0 número total de casos de sífilis adquirida notificados no Brasil foi de 119.800, em 2017 e de 158.051 casos, em 2018. Os homens costumam ser mais acometidos que as mulheres, geralmente adultos entre a terceira e a sexta décadas de vida (BRASIL, 2019).

Embora a doença típica primária envolva a genitália, manifestações orais da sífilis são observadas em aproximadamente 4 a $12 \%$ dos pacientes, refletindo suas práticas sexuais. Essas lesões são frequentemente descritas como úlceras indolores, comumente localizadas em língua, gengiva, palato mole e lábios e costumam aparecer entre 3 e 7 semanas após a infecção. No estágio secundário da doença, o envolvimento da cavidade bucal é mais comum (STREIGHT KL, et al., 2019). No caso apresentado, o paciente revelou lesões típicas do secundarismo sifilítico, placas ligeiramente elevadas, múltiplas, branco acinzentadas, evidenciadas em mucosa interna dos lábios superior e inferior. No palato mole, uma placa que repousava 
sobre base eritematosa foi evidenciada e duas outras lesões foram observadas em mucosa jugal e língua. Havia também linfonodos palpáveis em cadeia submandibular, o que tornava o quadro clínico sugestivo de sífilis, apesar de o paciente não referir sintomatologia sistêmica ou qualquer outra lesão pelo corpo.

Para a definição diagnóstica da sífilis, exames sorológicos devem ser solicitados como complemento ao exame clínico. Várias opções estão disponíveis no mercado, sendo fundamental o conhecimento desses exames para sua correta indicação. Duas grandes categorias apresentadas são: os testes treponêmicos e os não treponêmicos. Os não treponêmicos são indicados na suspeita de infecção, por apresentarem baixo custo e alta sensibilidade. São testes utilizados como triagem e detectam anticorpos inespecíficos, produzidos pelo organismo em resposta a antígenos presentes na superfície dos treponemas, mas não exclusivos deles. Por essa razão, em algumas situações (casos de colagenose, hepatite crônica, lúpus, mononucleose etc.) resultados falso-positivos podem ser evidenciados, o que justifica a realização de testes específicos (treponêmicos). Enquadram-se nessa categoria (testes não treponêmicos) o VDRL (Veneral Desease Research Laboratory) e a RPR (Rapid Plasma Reagina) (BRASIL, 2010; (CARLOS; AVELLEIRA; BOTTINO, 2006; KALINNI, 2016; SOUZA BC, 2017).

Nos testes treponêmicos, o antígeno empregado é o próprio Treponema pallidum, sendo pesquisada a presença de anticorpos no soro do paciente. Enquadram-se nesse grupo, exames de imunofluorescência indireta, como o FTA-abs (Fluorescent treponemal antibody absorption); de hemoaglutinação, como o MHATP (microhemaglutinação para Treponema pallidum); testes imunoenzimáticos, como o ELIZA (Enzymelinked immunossorbent assay) e testes moleculares, a exemplo da PCR (Polymerase Chain Reaction). Tais exames são indicados para confirmação da infecção. O primeiro a positivar é o FTA-abs, o que ocorre em torno de 10 dias da evolução do cancro duro (sífilis primária). Já na sífilis secundária, todos os testes sorológicos são reagentes e os testes quantitativos (não treponêmicos) tendem a apresentar títulos altos (CARLOS; AVELLEIRA; BOTTINO, 2006; BRASIL, 2010).

Caso a doença não seja diagnosticada no primeiro ou segundo estágios, o paciente pode evoluir para a sífilis terciária, ou apresentar grandes períodos de latência, causando a falsa impressão de tratamento bem sucedido, já que nesse período os sintomas desaparecem, mas os testes continuam positivos. Por esse motivo, é importante o acompanhamento sorológico do paciente para confirmação do sucesso do tratamento, sendo indicado os exames não trepônemicos (KALINNI, 2016).

O envolvimento da cavidade bucal pode ser um dos primeiros sinais da sífilis, fato que confere ao cirurgião dentista (CD) uma grande importância no controle da infecção, que se não identificada e tratada adequadamente, pode provocar desde mortes em bebês (se contraída durante a gestação), à infertilidade no adulto, além de problemas cardíacos, neurológicos e dermatológicos. Ao CD cabe o reconhecimento dos sinais e sintomas da doença, a educação do paciente e o encaminhamento adequado para o tratamento. Um fato que dificulta essa prática, no entanto, é a multiplicidade de aspectos clínicos que a doença pode apresentar, sendo confundida com outras lesões bucais mais comuns, a exemplo de lesões traumáticas e outras infecções, como o HIV, tuberculose, leishmaniose, gonorreia, micoses, além do linfoma, úlcera eosinofílica, carcinoma espinocelular, sialometaplasia necrosante e outras (EYER-SILVA WDA, et al., 2017; DE ANDRADE RS, et al., 2018). Outro fator complicador para o diagnóstico é o fato de as lesões bucais da sífilis serem assintomáticas e poderem regredir espontaneamente entre duas e 10 semanas, o que faz com que 30 a $40 \%$ dos pacientes fiquem sem diagnóstico. Também é importante destacar o despreparo de alguns CDs, que ao se dedicarem ao tratamento dos dentes e estruturas anexas, esquecem que a boca é sede frequente de inúmeras doenças, estando diretamente associada à saúde geral do indivíduo (ANDRADE RS, et al., 2018).

\section{CONSIDERAÇÕES FINAIS}

O caso apresentado reforça a importância da realização de um exame clínico criterioso, que não se limite à inspeção da cavidade bucal, mas que compreenda a investigação da saúde geral do indivíduo. Nessa perspectiva, não podem ser esquecidas, dentre os diagnósticos diferenciais, as doenças sistêmicas que acometem a cavidade bucal, a exemplo da sífilis. Seu reconhecimento precoce é de grande importância para

REAOdonto | Vol. 1 | e3446 | DOI: https://doi.org/10.25248/REAOdonto.e3446.2020 Página 6 de 7 
evitar consequências graves e complicações devastadoras, e a atuação do CD é fundamental para prevenir sua evolução, contágio e disseminação. A identificação das características clínicas da sífilis associada à solicitação de exames sorológicos, são, na maioria das vezes, as condições requeridas para o estabelecimento precoce do diagnóstico.

\section{REFERÊNCIAS}

1. ANGUS J, et al. As muitas faces da sífilis secundária: o ressurgimento de uma doença antiga. Clin Exp Dermatol., 2006; 31: 741-745.

2. AVELLEIRA CJR e BOTTINO G. Syphilis: diagnosis, treatment and control. An Bras Dermatol., 2006; 81(2): 111126.

3. BRASIL. Sífilis: Estratégias para Diagnóstico no Brasil. Ministério da Saúde, 2010; $1^{\circ}(1)^{\circ}: 100$.

4. BRASIL. Ministério da Saúde. Secretária de Vigilância em Saúde. Departamento de Vigilância, Prevenção e Controle das Infecções Sexualmente Transmissíveis do HIV/Aids e das Hepatites Virais (DIAHV). Boletim Epidemiológico de Sífilis. Brasil: Ministério, 2019.

5. CARMONA-LORDUY M, et al. Manifestaciones buçales de enfermidades de tranmisión sexual identificadas em tres servicios de estomatología em Sur América. Univer Salud, 2018; 20(1):82-88.

6. DE ANDRADE RS, et al. Oral findings in secondary syphilis. Medicina Oral Patologia Oral y Cirugia Bucal, 2018; 23(2); e138-e143.

7. EYER-SILVA WDA, et al. Secondary Syphilis Presenting as Glossodynia, Plaques en Prairie Fauchée, and a Split Papule at the Oral Commissure: Case Report and Review. Case Reports in Medicine, 2017; 2017; 1-5.

8. FRANCO ACM. O conhecimento dos formandos do curso de graduação em Odontologia de uma Universidade Pública de Pernambuco sobre DST/HIV/AIDS e medidas de biossegurança no ano de 2008. [Monografia]. Recife: Fundação Oswaldo Cruz; 2009

9. KALININ Y. Sífilis: aspectos clínicos, transmissão, manifestações orais, diagnóstico e tratamento. Odonto, 2016; 23(45): 65-76.

10. KENT ME e ROMANELLI F. Reexamining syphilis: an update on epidemiology, clinical manifestations, and management. Ann Pharmacother, 2008; 42: 22-36.

11. LITTLE JW. Syphilis: an update. Oral Surg Oral Med Oral Pathol Oral Radiol Endodontol, 2005; $100: 3-9$.

12. ORTEGA KL, et al. Sífilis secundária em um paciente VIH positivo. Med. Oral Patol. Oral Cir. Bucal., 2004; 9(1): 3338.

13. SEIBT C e MUNERATO MC. Secondary syphilis in the oral cavity and the role of the dental surgeon in STD prevention, diagnosis and treatment: a case series study. Brazilian Journal of Infectious Diseases, 2016: 20(4): 393-398.

14. SOLIS RN, et al. An Unusual Case of Tertiary Syphilis Behaving Like Tongue Squamous Cell Carcinoma. Journal of Investigative Medicine High Impact Case Reports. 2018; 6: 1-4.

15. SOUZA BC. Manifestações clínicas orais da sífilis. Revista Da Faculdade De Odontologia - UPF, 2017; 22(1): 82-85.

16. STREIGHT KL, et al. The oral manifestations of syphilitic disease: A case report. Journal of Medical Case Reports; 2019; 13(1): 4-6.

17. WHO. Guidelines for the Treatment of Treponema pallidum (syphilis). 2016

18. WHO. Estratégia global para o setor da saúde relativa a infecções sexualmente transmissíveis 2016-2021: Quadro de execução para a região africana; 2017; 6: 5-9. 